\title{
Caracterização da logística de distribuição de frutas, legumes e verduras na Central de Abastecimento de Campinas/SP
}

\author{
Characterization of fruit and vegetable distribution logistics of \\ Campinas Supply Center/SP
}

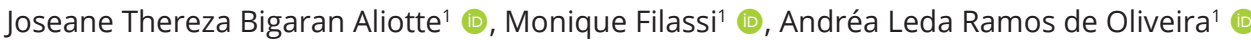

'Laboratório de Logística e Comercialização Agroindustrial (LOGICOM), Faculdade de Engenharia Agrícola, Universidade Estadual de Campinas (UNICAMP), Campinas (SP), Brasil. E-mails: esalqlogbigaran@gmail.com; moniquefilassi@gmail.com; aleda@unicamp.br

\begin{abstract}
Como citar: Aliotte, J. T. B., Filassi, M., \& Oliveira, A. L. R. (2022). Caracterização da logística de distribuição de frutas, legumes e verduras na Central de Abastecimento de Campinas/SP. Revista de Economia e Sociologia Rural, 60(spe), e252673. https://doi.org/10.1590/1806-9479.2021.252673
\end{abstract}

\begin{abstract}
Resumo: A redução das perdas e dos desperdícios de frutas, legumes e verduras (FLV) contribui para o aumento da oferta de alimentos. A identificação das perdas ao longo da cadeia logística de FLV possibilita a proposição de ações mitigadoras. O objetivo desta pesquisa é caracterizar as práticas operacionais da logística de distribuição das principais FLV comercializadas pela Central de Abastecimento (CEASA) de Campinas. A metodologia é dividida em duas partes: a primeira trata da estruturação do problema pela abordagem sistêmica por meio das técnicas conhecidas como gráfico Behavior Over Time (BOT) e modelo de loop causal, que subsidiam a segunda etapa com a aplicação de questionários aos comerciantes atacadistas para descrever as operações logísticas, validar os resultados encontrados na estruturação do problema e propor estratégias para a redução das perdas na comercialização. Os resultados indicaram que práticas ineficientes, como falta de transporte refrigerado, embalagens não adequadas, falta de rastreabilidade e manuseio excessivo, estão associadas às perdas. Conclui-se que a adoção do transporte refrigerado para manter a cadeia logística do frio é o diferencial para uma maior preservação da qualidade das FLV, além do uso de novas tecnologias de embalagem e treinamentos para os agentes da cadeia quanto às boas práticas pós-colheita.
\end{abstract}

Palavras-chave: alimentos perecíveis, cadeia de suprimentos, práticas pós-colheita, perdas e desperdício de alimentos.

\begin{abstract}
The reduction of fruits and vegetables losses and waste contributes to increasing food supply. Identification of losses along the logistics chain is essential for the development of mitigating actions. In this sense, this research aims to characterize the operational practices of the distribution logistics of the main fruit and vegetable trade in the Supply Center (CEASA) Campinas. The methodology is divided into two parts. The first deals with the structuring of the problem through a systemic approach through techniques known as the Behavior Over Time (BOT) graph. The causal loop model supported the second stage with the application of questionnaires with the wholesale traders to describe the logistical operations, validate the results found in structuring the problem, and from this perspective, propose strategies to reduce losses in trading. The results indicated that inefficient practices such as lack of refrigerated transport, inadequate packaging lack of traceability, and excessive handling are associated with losses. It is concluded that the adoption of refrigerated transport to maintain the cold logistics chain is the differential for greater preservation of the quality of fruits and vegetables, in addition to the use of new packaging technologies and training for chain agents regarding good post-harvest practices.
\end{abstract}

Keywords: perishable foods, supply chain, post-harvest practices, food losses and waste.

\section{Introdução}

O crescimento da demanda por alimentos na última década (Bloemhof \& Soysal, 2017; Saath \& Fachinello, 2018), aliado a fatos marcantes no que tange a aspectos demográficos e hábitos alimentares da população mundial, impõe novos desafios para a gestão da cadeia de 
suprimentos de alimentos (Wognum et al., 2011). Entre 2000 e 2016, houve um crescimento de $8 \%$ na expectativa de vida da população mundial (World Health Organization, 2019), e projeções para 2100 estimam que a população global deva chegar a 12,7 bilhões de pessoas (Uinited Nations, 2019). Adicionalmente, o comportamento dos consumidores por hábitos alimentares mais saudáveis tem ampliado a procura por frutas, legumes e verduras (FLV) (Mason-D'Croz et al., 2019; Yahia et al., 2019).

Os consumidores passaram a ficar mais exigentes quanto aos atributos de qualidade, frescor, diversidade, integridade, procedência e rastreabilidade associados aos alimentos. Nesse sentido, a sociedade está buscando cadeias alimentares mais sustentáveis e eficientes, de modo a garantir uma variedade na oferta de alimentos de qualidade ao longo do ano (Hospido et al., 2009).

No Brasil, nos últimos cinco anos, as vendas de alimentos naturais alavancaram 12,3\% a.a, enquanto no resto do mundo cresceram apenas $8 \%$. No ranking global, o Brasil lidera o quinto maior mercado de produtos saudáveis (Conselho Federal de Administração, 2019), e esse crescimento demonstra o potencial que o mercado de FLV apresenta para o país.

Embora a procura por alimentação saudável esteja em ascensão, o Brasil ainda apresenta déficit no consumo de FLV por indivíduo. Enquanto a Organização Mundial da Saúde (OMS) recomenda a ingestão de 400 gramas diárias, apenas 10\% da população tem consumido a quantidade indicada (Triches, 2020), dado que mostra o grau de insegurança alimentar que o país ainda enfrenta. Principalmente em regiões carentes em que o acesso aos alimentos é limitado, o fator custo é o que define a decisão de consumo, sendo comum a compra de um produto industrializado que traga mais saciedade, como é o caso dos produtos fast-food, ricos em gorduras e açúcares, em vez de um alimento fresco, como os FLV. O resultado desse processo é uma população mais obesa, o que, consequentemente, contribui para o surgimento de doenças crônicas não transmissíveis (DCNT), levando ao uso excessivo do sistema público de saúde.

Considerando as posições acerca do tema, há a ocorrência de duas situações: (1) necessidade de se ofertar alimentos saudáveis para uma parcela da população preocupada com os hábitos alimentares e (2) necessidade de se ofertar alimentos saudáveis para populações carentes que precisam de fontes importantes de vitaminas e minerais em sua dieta. Essas duas contextualizações direcionam para a seguinte problemática: como aumentar a oferta de alimentos saudáveis, se o uso da terra e da água para produção está cada vez mais escasso? Uma proposta é a mitigação das perdas e dos desperdícios de alimentos. Mas essa proposta direciona para outra questão: quais são as causas para perdas e desperdícios de alimentos e como reduzi-las?

Segundo a Food and Agriculture Organization (FAO) (Food and Agriculture Organization of the United Nations, 2011), um pouco mais de 30\% dos alimentos globalmente produzidos são desprezados por causa da perda da qualidade para a comercialização e/ou o consumo. No Brasil, estima-se que, da produção até a mesa do consumidor, as perdas de FLV possam chegar a 40\% (Rinaldi, 2011).

Diante desse panorama, o objetivo da pesquisa é caracterizar as práticas operacionais da logística de distribuição das principais FLV comercializadas pela Central de Abastecimento (CEASA) de Campinas. Sendo assim, essa caracterização teve como base o pensamento sistêmico, ao reconhecer que o todo vai além da soma de suas partes, com base na metodologia do gráfico Behavior Over Time (BOT) e modelo de loop causal (Sterman, 2000). A partir daí, foi realizada a aplicação de questionários aos comerciantes atacadistas para descrever as operações logísticas que subsidiam a proposição e a validação das estratégias mitigadoras de perdas. 
O estudo apresenta literatura relevante, metodologia utilizada, dados coletados e análises descritivas. O artigo foi dividido nas seguintes seções: 1 ) introdução; 2 ) breve revisão de literatura sobre perdas e desperdícios de alimentos e suas causas; 3) desenvolvimento da metodologia, com a descrição da abordagem sistêmica da estruturação do problema e aplicação dos questionários para traçar as estratégias de redução de perdas; 4) resultados e discussão; e 5) conclusões.

\section{Revisão de Literatura}

Belik et al. (2012) observam que as perdas e os desperdícios existentes nas etapas de comercialização do modelo produtivo predominante contrastam com a parcela da população que se encontra em situação de insegurança alimentar. A pobreza e a desnutrição existentes nos países em desenvolvimento requerem eficiência e sustentabilidade dos sistemas alimentares (Fehr \& Romão, 2001; Belik et al., 2012). Nesse sentido, faz-se necessária a identificação das causas dessas perdas para propor recomendações para sua mitigação (Belik et al., 2012).

As perdas e os desperdícios ocorrem desde o momento da produção, distribuição, armazenamento e comercialização, até chegar à mesa do consumidor. Vilela et al. (2003) explicam que as perdas e os desperdícios começam no campo por ocasião da colheita, passam pela comercialização nas centrais de abastecimento e demais atacadistas, na sequência pela rede varejista até chegar aos consumidores intermediários e finais.

Cattaneo et al. (2020) enfatizam que, na última década, houve um crescimento exponencial de pesquisas com interesse pela questão das perdas e dos desperdícios de alimentos, e isso aumentou a conscientização sobre o tema e suas implicações.

Para melhor compreensão, há uma diferenciação entre perdas e desperdícios. As perdas ocorrem quando há uma diminuição na quantidade ou na qualidade do alimento nos estágios da cadeia de suprimentos, relacionadas às atividades de pós-colheita e infraestrutura, o que, consequentemente, reduz a quantidade ofertada à população (Gustavsson et al., 2013; Food and Agriculture Organization of the United Nations, 2019; Cattaneo et al., 2020). Porat et al. (2018) explicam que as perdas qualitativas ocorrem em função da má qualidade em termos de cor, tamanho, forma, sabor e outros aspectos, que resultam em baixa aceitabilidade pelo consumidor, enquanto as perdas quantitativas ocorrem por causa da deterioração fisiológica, mecânica e patológica, ou a combinação destas. O desperdício de alimentos, por sua vez, acontece durante a comercialização no varejo e consumo nas residências, portanto está relacionado ao comportamento humano. As perdas têm caráter não intencional, enquanto o desperdício parte de uma condição intencional (Gustavsson et al., 2013; Food and Agriculture Organization of the United Nations, 2019; Cattaneo et al., 2020).

Para as FLV, as causas das perdas são variadas, indo desde a falta de adoção de protocolos simples de colheita, passando por condições inadequadas de transporte e acondicionamento com ausência de refrigeração, excesso de manuseio dos produtos, chegando até as falhas de gestão na comercialização para reduzir o tempo entre a colheita e o consumo (Lana, 2018; Henz, 2018).

Ščetar et al. (2010) argumentam que os dados quantitativos sobre as perdas e os desperdícios são questionáveis em função da dificuldade de aferir a condição do produto nas diferentes etapas da cadeia de distribuição. De acordo com Belik et al. (2012), a ausência de critérios e parâmetros sistematizados que permitam mensurar as perdas e os desperdícios de alimentos é que traz dificuldades para a condução de pesquisas dessa natureza. 
Nos países em desenvolvimento, mais de $40 \%$ das perdas ocorrem nos níveis de pós-colheita e processamento (Food and Agriculture Organization of the United Nations, 2011) em razão das limitações técnicas de colheita, tecnologia inadequada e/ou infraestrutura de armazenamento deficiente (Kumar \& Kalita, 2017), enquanto em países desenvolvidos mais de 40\% acontecem no varejo e no consumo final (Food and Agriculture Organization of the United Nations, 2011).

Belik et al. (2012) reconhecem que a mais completa pesquisa sobre perdas de alimentos foi desenvolvida pelo Economic Research Service, divisão do Departamento de Agricultura dos Estados Unidos (USDA), em que as perdas foram divididas em três fases do processo produtivo: campo, nível do atacado e varejo.

Freire Junior \& Soares (2014) relatam quais são as principais perdas relacionadas às fases de produção e pós-colheita para FLV: (1) produção - desconhecimento de técnicas de plantio, seleção de sementes e cultivares, espaçamento inadequado entre plantas, erros no preparo do solo, técnicas inadequadas de manejo da cultura (adubação, irrigação, podas) e falha ou ausência no controle integrado de pragas e/ou moléstias durante as fases pré e póscolheita; (2) pós-colheita - falta de pessoal habilitado na colheita e no galpão de embalagem, desconhecimento do ponto ideal de colheita, más condições climáticas durante o período da colheita, uso de tecnologias e equipamentos inadequados de colheita e armazenamento, embalagens e transporte inadequados.

As políticas agrícolas em curso não têm explorado a eficiência geral das cadeias produtivas de alimentos, porque priorizam os aumentos de produtividade e produção sem considerar a oferta líquida de alimentos. Uma vez que os maiores índices de perdas de alimentos ocorrem na logística, os esforços direcionados para a manutenção dos ganhos de produtividade são invalidados (Belik et al., 2012). Portanto, a redução efetiva das perdas e dos desperdícios demanda ações e medidas que sejam de fato implementadas (Vilela et al., 2003).

Para que as FLV cheguem com qualidade ao consumidor, é necessária uma logística eficiente. Para que a mitigação das perdas e dos desperdícios aconteça, é necessário investigar as etapas da cadeia de distribuição em que elas são mais recorrentes. Neste caso, a logística, entendida em seu contexto amplo, envolve o planejamento, a implementação e o controle do fluxo e da armazenagem de produtos e informações desde a origem até o consumo, atendendo às necessidades dos consumidores (Council of Supply Chain Management Professionals, 2020).

Ao melhorar o desempenho da cadeia, pode-se aumentar o acesso ao produto em quantidade e qualidade, muitas vezes reduzir o custo para o consumidor, melhorar o lucro dos agricultores, além de estar contribuindo para a promoção da segurança alimentar.

Além disso, as FLV possuem diferentes níveis de perecibilidade, principalmente por causa da intensidade de respiração de cada espécie, e, portanto, necessitam de embalagens e transportes distintos para que cheguem até a população com qualidade. Portanto, os cuidados com a póscolheita contribuem para manter a qualidade por meio da aparência, textura, sabor e valor nutritivo. São considerados produtos perecíveis, conforme as Resoluções RDC $n^{\circ} 216 / 04$ e $n^{\circ}$ 43/15, alimentos que, de acordo com sua natureza ou composição, necessitam de condições especiais de temperatura ou ventilação para a sua conservação (Sousa \& Aguiar, 2019).

Tão importante quanto um transporte eficiente para a preservação do produto, é também o processo de comercialização por atacadistas. Por isso, outro fator que merece destaque são as operações realizadas pelas Centrais de Abastecimentos, denominadas CEASA e CEAGESP, destinadas, principalmente, à comercialização de produtos hortifrutigranjeiros no atacado.

As Centrais Atacadistas são as responsáveis pelos maiores volumes comercializados de frutas e vegetais no Brasil (Companhia Nacional de Abastecimento, 2020). As CEASAs formam uma rede descentralizada, com 69 unidades, e são as principais responsáveis pelo abastecimento 
alimentar da população urbana brasileira e pela formação de preços, escala comercial e padrões de comercialização (Cunha, 2006, 2015; Cunha \& Belik, 2012). As CEASAs são importantes agentes dos sistemas agrícolas dos governos locais, concentrando, ainda que de forma não sistemática, iniciativas relevantes para as políticas agrícolas estaduais, bem como as políticas de segurança alimentar.

Em 2019, foram comercializadas 12,1 milhões de toneladas de hortifrutigranjeiros, representando R $\$ 34,7$ bilhões (Companhia Nacional de Abastecimento, 2021). No Brasil, a CEASA Campinas (Campinas/SP) e a CEAGESP (São Paulo/SP) são referências na atividade atacadista e, juntas, comercializaram 3,7 milhões de hortifrutigranjeiros, que representaram $30 \%$ do volume comercializado pelas centrais.

Dada a proporção do volume transacionado e diante de uma proeminente perspectiva de crescimento do mercado de alimentação saudável, os atacadistas precisam melhor administrar aspectos logísticos durante o transporte da mercadoria comprada para revenda. De modo geral, a eficiência com que são realizadas as operações logísticas pelos stakeholders dessa cadeia é determinante para a preservação da qualidade do produto e um maior tempo de prateleira.

\section{Metodologia}

A presente pesquisa é de caracterização (Volpato, 2013), em que foram descritas as operações logísticas do transporte de FLV com destino ao centro atacadista. Para descrevê-las, primeiramente houve a necessidade de se analisar como as ações de cada stakeholder têm impactado a logística dessa cadeia. Diante disso, o pensamento sistêmico foi adotado como principal abordagem. De natureza holística, essa abordagem considera como as interações complexas entre diferentes stakeholders impactam o sistema como um todo (Elias \& Davis, 2018).

A metodologia de pensamento sistêmico e modelagem, desenvolvida por Maani \& Cavana (2000), propõe soluções estratégicas para o problema identificado no gráfico Behavior Over Time(BOT), o qual foi analisado por meio da construção do modelo de loop causal. A estrutura da metodologia sistêmica deste trabalho foi dividida em duas fases e cinco etapas (Tabela 1).

Tabela 1 - Estrutura da metodologia sistêmica

\begin{tabular}{ll}
\multicolumn{1}{c}{ Fases } & \multicolumn{1}{c}{ Etapas } \\
1. Estruturação do problema & $\begin{array}{l}\text { i. Desenvolvimento do gráfico de comportamento ao longo do tempo (BOT) } \\
\text { 2. Modelagem de loop causal }\end{array}$ \\
& $\begin{array}{ll}\text { i. Identificação das variáveis } \\
\text { ii. Desenvolvimento do modelo de loop causal } \\
\text { iii. Análise do modelo de loop causal }\end{array}$ \\
\hline
\end{tabular}

Fonte: adaptada de Elias (2008).

\section{Fase 1: Estruturação do problema}

Essa fase envolve a estruturação sistemática da situação-problema (Maani \& Cavana, 2000). Para esse fim, um gráfico BOT (Sterman, 2000) deve ser desenvolvido, e os stakeholders devem ser identificados.

i. Desenvolvimento do gráfico de comportamento ao longo do tempo (BOT): um gráfico BOT é uma ferramenta usada para mostrar tendências e padrões das principais variáveis relacionadas à situação-problema de um sistema que está sendo analisado. Nesse caso, 
são atributos logísticos que possam demonstrar a eficiência de distribuição para produtos FLV. Os padrões identificados no BOT podem indicar variações e tendências, por exemplo, crescimento, declínio, oscilações ou uma combinação deles, durante um período prolongado de tempo, geralmente de vários meses a vários anos. Os elementos importantes capturados pelo BOT são desenhados em um sentido aproximado, sem valores numéricos exatos (Maani \& Cavana, 2000).

ii. Análise dos stakeholders. a identificação das partes interessadas que podem afetar ou são afetadas pelo sistema é importante, pois ajuda a estruturar a situação-problema e contribui para a investigação de quais são as variáveis quantitativas e qualitativas que estão por trás do comportamento das variáveis apresentadas no gráfico BOT. Nesta etapa, são características das operações logísticas praticadas pelos comerciantes atacadistas especializados em FLV, a fim de explicar o comportamento complexo capturado no gráfico BOT.

\section{Fase 2: Modelagem de loop causal}

Na segunda fase, um modelo de loop causal (Sterman, 2000) deve ser desenvolvido para capturar a estrutura subjacente do sistema. O modelo de loop causal avalia as relações de causa e efeito entre as diferentes variáveis que impactam o sistema (Maani \& Cavana, 2000).

i. Identificação das variáveis: com base nas diretrizes fornecidas por Sterman (2000), as variáveis são extraídas das informações coletadas nas etapas anteriores e utilizadas para desenvolver o modelo do loop causal.

ii. Desenvolvimento do modelo de loop causal: o modelo é desenvolvido a partir da ligação das principais variáveis identificadas que estão relacionadas às variáveis do gráfico BOT. Sendo assim, cada variável apresentada está ligada por meio de setas às demais variáveis, a fim de demonstrar a relação de causa e efeito dos loops de feedback (Maani \& Cavana, 2000). Uma seta que apresenta vínculo positivo (+) indica que, se a causa de uma variável aumentar, o efeito sobre a próxima variável também aumentará, e se a causa de uma variável diminuir, o efeito sobre a próxima variável também diminuirá. Já um vínculo negativo (-) significa o oposto: se a causa de uma variável aumentar, o efeito sobre a próxima variável diminuirá, e se a causa de uma variável diminuir, o efeito sobre a próxima variável aumentará (Sterman, 2000).

iii. Análise do diagrama de loop causal: para criticar o modelo de loop causal, uma análise de cada um dos loops de feedback formados deve ser realizada. Os loops de feedback podem ser de reforço ("R") ou de equilíbrio ("B"). Loops de reforço refletem sistemas de feedback positivo e podem representar ações crescentes ou em declínio, ou seja, não ter ou ter um número par de links negativos (-) significa que é um loop de reforço. Diferentemente dos loops de reforço, os loops de equilíbrio refletem os sistemas de feedback negativo e buscam estabilidade ou retorno ao controle, ou seja, ter um número ímpar de links negativos (-) significa que é um loop de equilíbrio (Sterman, 2000).

Em um diagrama de loop causal, é possível visualizar os loops de feedback em interação. A estrutura do sistema é capturada pelo diagrama de loop causal, e seus loops de feedback permitem a identificação do comportamento contraintuitivo que vem ocorrendo no sistema analisado. Esse comportamento é inicialmente demonstrado pelo gráfico BOT.

Essa metodologia permite que mudanças estruturais de longo prazo sejam planejadas, a fim de mudar o comportamento do sistema. Correções rápidas de curto prazo na estrutura podem não ser úteis (Senge, 1990). 
A partir dessas fases, a metodologia utilizada foi baseada na avaliação qualitativa das informações levantadas por meio de questionário semiestruturado (Apêndice 1) aplicado aos comerciantes atacadistas da CEASA Campinas.

A CEASA Campinas é um importante centro de comercialização de FLV e de outros produtos perecíveis para o estado de São Paulo, sendo responsável pelo abastecimento de mais de 500 municípios. São mais de 580 comerciantes atacadistas, distribuídos em cerca de 940 lojas (Central de Abastecimento de Campinas, 2020). A seleção foi motivada por: (i) facilidade de acesso e coleta de informações com os comerciantes; (ii) triênio 2017-2019, foi comercializado 1,80 milhão de toneladas de alimentos, sendo que 560 mil toneladas eram de FLV, posicionandose como a oitava maior central atacadista do país (Companhia Nacional de Abastecimento, 2021); (iii) destinação dos produtos não comercializados para o Instituto de Solidariedade para Programas de Alimentação (ISA). O Instituto é uma organização não governamental que funciona dentro da CEASA Campinas. O ISA surgiu com o objetivo de combater a fome e o desperdício, garantindo o aproveitamento do excedente de frutas e vegetais para incentivar as doações dos comerciantes atacadistas da CEASA Campinas.

Os cinco produtos escolhidos (laranja, mamão, alface, tomate e batata) são representativos dentro de suas respectivas categorias, a saber: (1) frutas e (2) hortaliças; (a) vegetais de folhas, flores e caule, (b) fruto e (c) raiz, bulbo, tubérculo e rizoma. Esses produtos estão entre os mais consumidos pela população brasileira, segundo a última Pesquisa de Orçamentos Familiares (POF) 2017-2018 (Instituto Brasileiro de Geografia e Estatística, 2019a).

Foram entrevistados 71 comerciantes atacadistas da CEASA Campinas entre outubro de $2019 \mathrm{e}$ janeiro de 2020. Os entrevistados representaram a totalidade dos comerciantes que negociavam exclusivamente o produto analisado. Os questionários foram aplicados individualmente, e o universo amostral foi composto por 6 comerciantes atacadistas de alface, 14 de batata, 13 de laranja, 19 de mamão e 19 de tomate (taxa de resposta de 97,3\%). Para manter o anonimato dos atacadistas, eles foram codificados com números sequenciais de 1 a 71 . 0 questionário aplicado consta no Apêndice 1.

Essa abordagem metodológica é conhecida como rapid appraisal e foi aplicada por Dunn (1994), Beebe (1995) e, com foco nas estratégias para a gestão das cadeias de suprimentos, Akintoye et al. (2000) e Sukati et al. (2012). Esse método utiliza dados de fontes secundárias em conjunto com entrevistas semiestruturadas, nas quais dados e/ou informações detalhadas são necessários para compreender a dinâmica do setor avaliado.

\section{Resultados e Discussão}

\subsection{Estruturação do problema}

A seleção das variáveis segue a abordagem Maani \& Cavana (2000), em que é necessário avaliar o comportamento ao longo do tempo de variáveis ou características que representem o problema em questão. Os estudos de Lana (2018) e Henz (2018) também fundamentaram a escolha das variáveis, uma vez que as perdas de FLV têm nas fases de transporte e comercialização as principais causas, e apontaram que a ausência de refrigeração é uma das principais razões de perdas de FLV no Brasil nessa fase.

Desta forma, as três variáveis com estatísticas disponíveis para um período de pelo dez anos e que são capazes de expressar o problema de perdas na distribuição de FLV na CEASA Campinas foram: a receita gerada pela comercialização dos produtos hortifrutigranjeiros comercializados 
pela CEASA Campinas entre 2009-2019 (Companhia Nacional de Abastecimento, 2020); a estimativa de perdas entre 2009-2019, que foi calculada a partir do volume comercializado pela CEASA Campinas em função do índice de perdas de 11,6\% estimado pela Food and Agriculture Organization of the United Nations (2016) para América Latina; e o número de implementos frigorificados por reboque/semirreboque para caminhões vendidos e emplacados no Brasil, contabilizado pela Associação Nacional dos Fabricantes de Implementos Rodoviários, entre 2009-2019 (Associação Nacional dos Fabricantes de Implementos Rodoviários, 2020). Uma vez que cada variável apresenta diferentes unidades de medida, a normalização dos dados foi feita para que fosse possível avaliar o comportamento e a evolução das variáveis ao longo do tempo (Figura 1).

O comportamento da variável receita das FLV vem crescendo nos últimos cinco anos. As variáveis estimativas de perdas e emplacamento têm comportamentos opostos, o que pode implicar, em um primeiro momento, uma relação de causa e consequência (Figura 1). A partir de 2016, houve uma maior demanda no número de emplacamento de reboque/semirreboque frigorífico, o que pode contribuir para um aumento nas receitas de FLV, principalmente porque pode existir uma expectativa de queda nas perdas desses produtos.

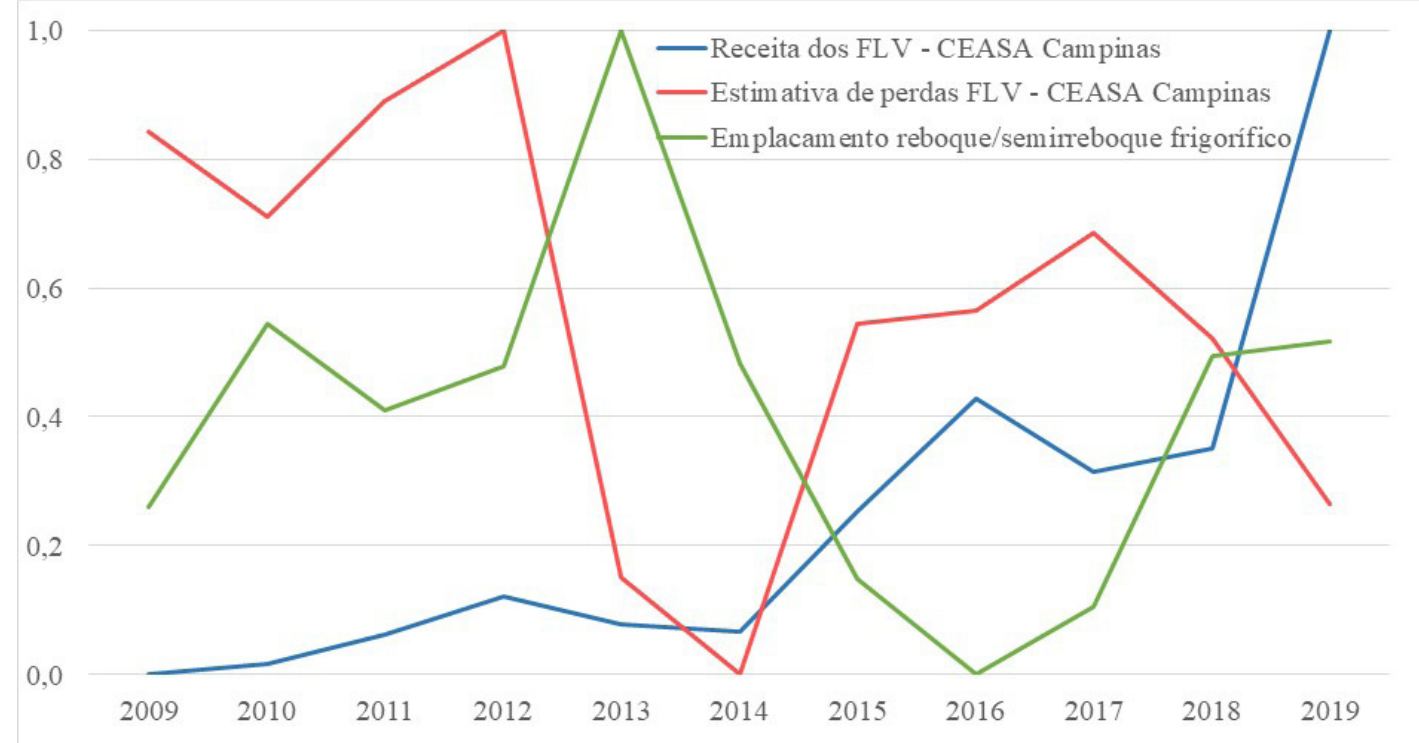

Figura 1 - Comportamento do valor e perdas das FLV da CEASA Campinas e emplacamento de implementos rodoviários frigorificados.

Fonte: Companhia Nacional de Abastecimento (2020), Food and Agriculture Organization of the United Nations (2016) e Associação Nacional dos Fabricantes de Implementos Rodoviários (2020).

\subsection{Modelagem de loop causal}

O modelo de loop causal desenvolvido incluiu três ciclos de feedback de reforço: as perdas, o emplacamento e o valor das FLV (Figura 2). Os critérios associados foram: (1) tipo de transporte, (2) agente responsável pelo transporte/intermediário, (3) rastreabilidade, (4) acondicionamento em câmara fria, (5) tipos de embalagem e (6) operações de carga/descarga. 


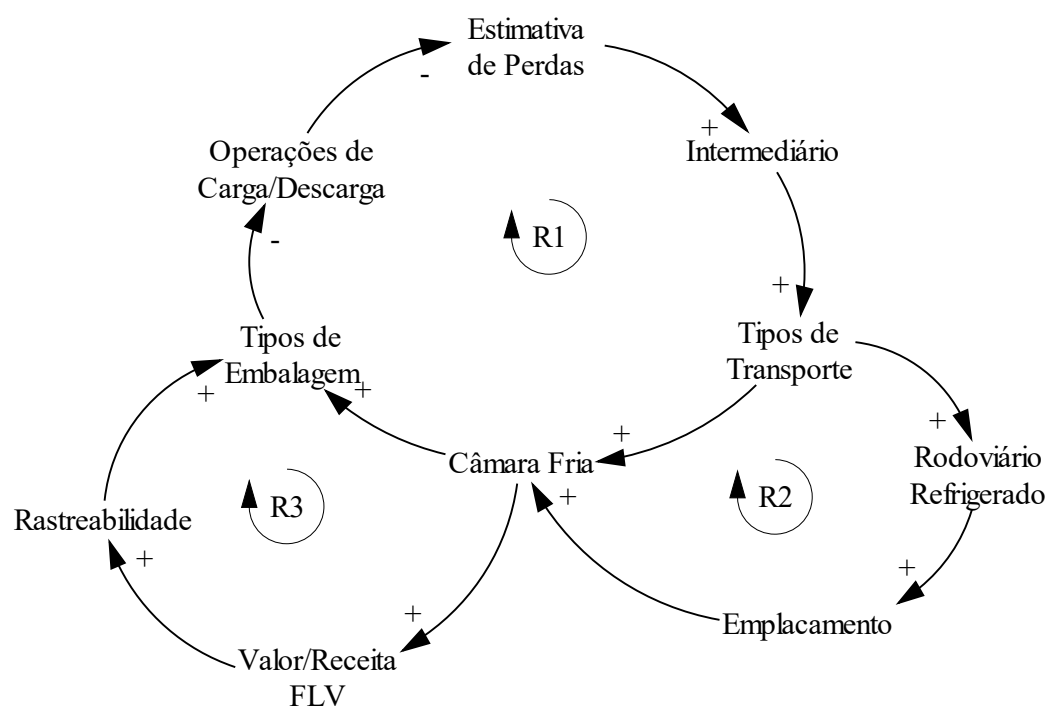

Figura 2 - Modelo de loop causal

Loop estimativa de perdas loop (R1): quanto maior o número de intermediários, maior a demanda por tipos de transporte em circulação; quanto maiores os tipos de transporte, maior a chance de os veículos possuírem câmara fria; quanto maior o número de câmara fria, maior a necessidade de embalagens adequadas para manter os produtos frescos e seguros; quanto maior o número de embalagens adequadas, menor a necessidade de operações e manipulações das FVL; quanto menos manipulações, mais preservado o produto e menores as estimativas de perdas; quanto menores as perdas, mais seguros os produtores e os atacadistas se sentem em utilizar o serviço dos intermediários para o transporte dos produtos (Figura 2).

Loop emplacamento loop (R2): quanto maior o número de opções de diferentes transportes em circulação, maior o número do transporte rodoviário refrigerado; quanto maior o número de veículos refrigerados em circulação, maior o número de emplacamentos de veículos que possuem câmara fria.

Loop valor/receita FLV loop (R3): quanto maior o número de câmaras frias, maiores as quantidades de alimentos; quanto maior o volume comercializado, maior a necessidade de se diferenciar o produto (procedência) por meio de investimentos em ferramentas como a rastreabilidade, que garante a qualidade do produto; com uma maior rastreabilidade, mais embalagens adequadas e que levem em consideração questões como o meio ambiente serão inseridas nesse mercado; em contrapartida, o manuseio será menor, o que acarreta uma menor estimativa de perdas.

\subsection{Análise descritiva}

Com as informações obtidas por meio de questionário aplicado para o levantamento da caracterização das operações logísticas de transporte de FLV na etapa de distribuição (do campo até a CEASA Campinas), chegaram-se às seguintes características: (1) tipo de transporte, (2) agente responsável pelo transporte, (3) rastreabilidade, (4) acondicionamento em câmara fria, 
(5) tipos de embalagem, (6) troca de embalagem e (7) manipulação da carga. Também foram questionadas percepções dos atacadistas associadas às perdas.

As operações levantadas são similares a estudos que, de acordo com Porat et al. (2018), indicam que, em países em desenvolvimento, as perdas e os desperdícios de alimentos são resultantes, em grande parte, da má gestão e limitações técnicas de colheita, armazenamento, transporte e atividades de processamento, por causa da falta de instalações de refrigeração adequadas, infraestrutura e embalagens.

A seguir, são detalhadas as práticas operacionais da logística de distribuição das FLV selecionadas: alface, batata, laranja, mamão e tomate.

\subsubsection{Tipo de transporte}

No Brasil, conforme relatado pelos atacadistas, o modal de transporte predominante de distribuição de FLV era o rodoviário. Os modelos-padrão de caminhão para esse fim são: caminhão-baú refrigerado, caminhão-baú não refrigerado e caminhão graneleiro, denominado carroceria aberta. No caso do graneleiro, é comum o uso de lona para cobrir as FLV e evitar exposição direta ao sol, frio e orvalho.

Para melhor compreensão, vale destacar a diferença entre caminhão-baú refrigerado e caminhão-baú frigorificado. Ambos possuem o sistema de câmara fria, responsável pela regulação da temperatura para melhor acondicionamento do produto. Os atacadistas explicaram que o que difere os modelos é a temperatura empregada, ou seja, o baú frigorificado é usado, principalmente, para o transporte de carnes e pães em temperaturas inferiores a $0^{\circ} \mathrm{C}$. No caso do baú refrigerado, em que se enquadra o transporte de frutas e vegetais, a temperatura de armazenamento dos produtos pode variar de $0^{\circ} \mathrm{C} a+18^{\circ} \mathrm{C}$.

Portanto, produtos perecíveis, como as FLV, necessitam de temperatura controlada para uma melhor conservação, porém, por causa de o transporte refrigerado ter um custo mais elevado, poucos atacadistas empregam essa tecnologia. O produto mamão foi o que mais empregou o transporte refrigerado, seguido pela alface (Figura 3). Como ambos os produtos possuíam maior perecibilidade (senescência) em relação aos demais produtos analisados, era esperado um maior uso de caminhões refrigerados. No entanto, tanto a alface quanto o mamão utilizavam menos de $50 \%$ desse tipo de transporte. No caso do tomate de perecibilidade similar, não foi feita a utilização desse sistema.

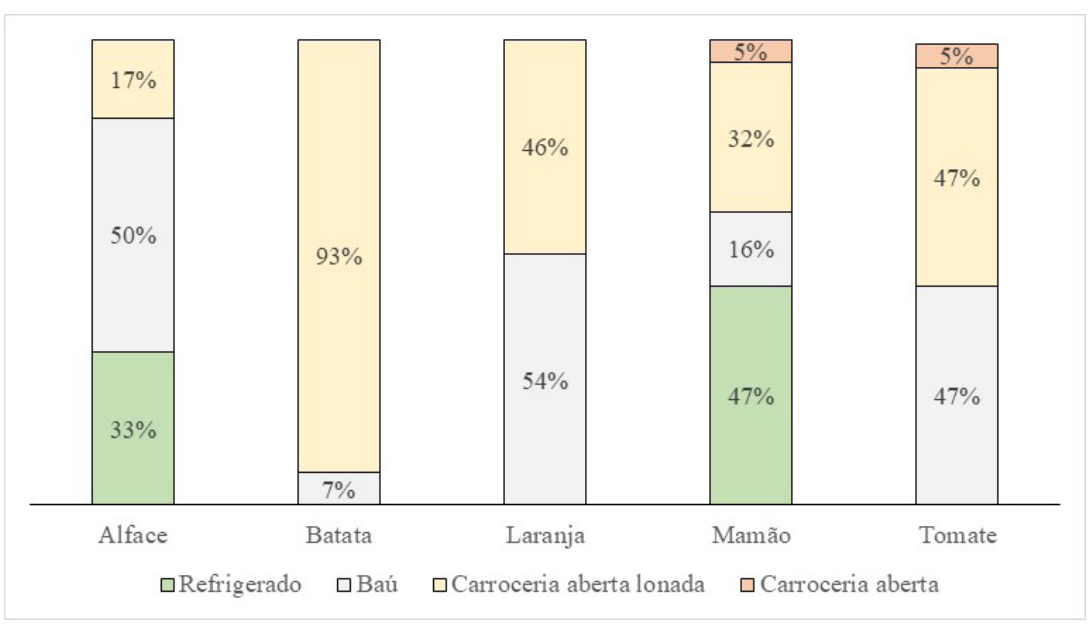

Figura 3 - Transporte por tipo de carroceria 
Em campo, foi notado que as rotas para alface eram de curta quilometragem, diferentemente do mamão, que era caracterizado por rotas longas. Já no caso do tomate, as rotas eram variadas (curtas e longas), fazendo com que os agentes atacadistas recebessem produtos de diferentes qualidades. De acordo com a sazonalidade, no período de baixa oferta, embora o preço seja elevado e o produto apresente baixa qualidade, o mercado consegue se abastecer, uma vez que a demanda é pouco elástica, ou seja, uma mudança nos preços provoca pequenas variações no comportamento da demanda (Mankiw, 2014). Ocorre que, quando o mercado está com maior oferta, produtos de melhor qualidade são comercializados a preços mais baixos.

Uma das explicações pelo não uso do refrigerado, segundo os atacadistas, é a busca por menor custo do transporte, o que leva à falsa sensação de que o frete refrigerado pode ser menos competitivo ao repassar o custo para o preço de comercialização. Porém, a empregabilidade do transporte refrigerado poderia proporcionar tomates de qualidade superior e maior oferta, principalmente, na baixa temporada de produção, pois aumentaria o tempo de prateleira. Além disso, tomates com injúrias ocasionadas pela colheita ou pelo mau manuseio têm seu processo de deterioração acelerado quando não utilizado o transporte refrigerado.

Freire Junior \& Soares (2014) citam como fatores de perda no transporte: caminhões antigos com sistema de suspensão que não amortece os impactos, mau acondicionamento de produtos, embalagens inadequadas, falta de padrão de qualidade dos produtos, falta de armazenagem refrigerada, produtos não paletizados, carregamento realizado caixa por caixa ao sol e manuseio inadequado com mistura de cargas de diferentes espécies. Além disso, o mau estado de conservação das rodovias e estradas não pavimentadas leva a constantes trepidações, causando o aumento das injúrias.

Mesmo após a colheita, as FLV continuam a passar por processos biológicos, portanto é comum a variação nas taxas de respiração e produção de etileno (Ščetar et al., 2010). Hospido et al. (2009) explicam que FLV são seres vivos; assim, quando respiram, liberam gases e outros materiais no ambiente. Essas atividades levam à sua deterioração durante o tempo em trânsito e armazenamento, o que, em condições de temperatura e umidade inadequadas, torna-se mais acelerado. Sendo assim, o transporte refrigerado contribui para a redução da velocidade do processo biológico.

Outro problema relatado refere-se à capacidade de carga dos caminhões. Freire Junior \& Soares (2014) sugerem que, para que ocorra a redução de perdas na cadeia, é necessário estabelecer critérios de capacidades de cargas máximas por produto, aplicar programas de conscientização aos motoristas, estimular o uso de caminhão refrigerado e verificar se a altura e a largura da carroceria são compatíveis com a altura da plataforma de recepção.

\subsubsection{Agente responsável pelo transporte}

Outro fator importante foi avaliar quem era o responsável pelo transporte entre a propriedade rural e o centro atacadista, uma vez que é esse o agente que responde pela carga. Os agentes foram divididos em três categorias: atacadista, produtor e terceiro (Tabela 2).

Os atacadistas entendiam que, quando eles próprios operavam o transporte, eram mais cuidadosos com o acondicionamento, carregamento e transporte do produto. Conforme aponta Oliveira et al. (2008), um transporte malfeito pode prejudicar a carga, por isso recomenda-se que o veículo esteja limpo, coberto, com boa ventilação e livre de vetores e pragas urbanas. Além disso, deve-se tomar cuidado para não causar lesão ao produto no momento de acomodá-lo no caminhão, por isso as caixas devem ser cuidadosamente dispostas. 
Tabela 2 - Agente responsável pelo transporte

\begin{tabular}{cccc} 
& Atacadista & Produtor & Terceiro \\
Alface & $83,3 \%$ & $16,7 \%$ & - \\
Batata & $85,7 \%$ & - & $14,3 \%$ \\
Laranja & $53,8 \%$ & $23,0 \%$ & $23,2 \%$ \\
Mamão & $10,5 \%$ & $0,5 \%$ & $89,0 \%$ \\
Tomate & $63,1 \%$ & $0,5 \%$ & $36,4 \%$ \\
\hline
\end{tabular}

Em relação ao transporte feito por terceiros, existem dois casos: frete contratado pelo permissionário ou frete contratado pelo produtor.

No caso do mamão, como o maior volume com destino à CEASA Campinas tem produção com origem na região Nordeste do Brasil e fragmentada por diversos municípios produtores, é comum a contratação de fretes de terceiros. Foi observado que $89 \%$ do mamão transportado era feito por terceiros. Além disso, por causa das longas rotas, o produto levava em média dois dias para chegar ao centro atacadista, afetando diretamente a qualidade do produto quando não utilizado o transporte refrigerado.

No caso da alface ocorreu o oposto, ou seja, 83,3\% do transporte era feito pelo próprio atacadista em rotas curtas, uma vez que a produção estava nos cinturões verdes próximos ao centro de comercialização.

Para a batata, o percentual de transporte feito pelo próprio atacadista também foi alto, $85,7 \%$. A batata apresenta locais de produção variados, porém seu maior volume é proveniente de regiões mais próximas à CEASA Campinas. No Brasil, os maiores estados produtores de batata são: Minas Gerais, Paraná, São Paulo, Rio Grande do Sul, Bahia, Goiás e Santa Catarina (Instituto Brasileiro de Geografia e Estatística, 2019b). A produção da batata ocorre em três safras anuais: 1 - plantação de agosto a dezembro, com colheita de novembro a fevereiro; 2 - plantação de janeiro a março, com colheita de abril a julho; e 3 - plantação de abril a julho, com colheita de julho a outubro (Marcomini \& Patino, 2020).

Os atacadistas relataram que as batatas provenientes do estado do Paraná eram as que apresentavam melhor qualidade para comercialização, enquanto as de Minas Gerais possuíam qualidade inferior. Esse fato se deve à qualidade do solo, gerando, assim, produtos pequenos e de coloração esverdeada. Além disso, em época de alta de preço, os produtores colhem a batata antecipadamente, afetando também a qualidade do produto.

\subsubsection{Rastreabilidade}

Nos últimos anos, o consumidor tem demandado mais informações sobre o produto adquirido, levando grandes redes varejistas de alimentos a investir em rastreabilidade, por isso o rastreamento tem sido uma forma de garantir aspectos de segurança do alimento, qualidade e acesso a diversos mercados (Muralikumar \& Nardi, 2018). Essa procura por rastreabilidade vem ganhando cada vez mais adeptos, de modo que mesmo pequenos produtores estão implementando esses sistemas, uma vez que produtos rastreados atendem às exigências sanitárias.

Os atacadistas estão sendo fiscalizados, mas ainda sem a aplicação de multas aos que ainda não praticam a rastreabilidade. Porém, esse cenário está passando por mudanças, e a ausência dessa prática pode implicar perdas de mercado. Durante a aplicação dos questionários, muitos dos atacadistas não tinham conhecimento quanto à prática da rastreabilidade. 
Tabela 3 - Responsável pela rastreabilidade

\begin{tabular}{cccc} 
& Atacadista & Produtor & Não faz \\
Alface & $33,3 \%$ & - & $66,7 \%$ \\
Batata & $57,1 \%$ & $28,6 \%$ & $14,3 \%$ \\
Laranja & $38,4 \%$ & $30,8 \%$ & $30,8 \%$ \\
Mamão & $47,4 \%$ & $15,8 \%$ & $36,8 \%$ \\
Tomate & $31,6 \%$ & - & $68,4 \%$ \\
\hline
\end{tabular}

É possível notar que a alface e o tomate eram rastreados apenas pelos atacadistas (Tabela 3), e isso pode ser explicado pelo fato de serem comercializados por pequenos produtores familiares, que podem apresentar um quadro reduzido de funcionários, o que limita a implantação dessa prática operacional.

\subsubsection{Acondicionamento em câmara fria}

Alimentos mantidos sob temperatura apropriada, de acordo com as características particulares de conservação - alface $\left(1\right.$ a $\left.6^{\circ} \mathrm{C}\right)$, batata $\left(12\right.$ a $\left.15^{\circ} \mathrm{C}\right)$ (Oliveira et al., 2008), laranja (em torno de $1^{\circ} \mathrm{C}$ ) (Kluge et al., 2007), mamão (em torno de $10^{\circ} \mathrm{C}$ ) (Silva \& Soares, 2001) e tomate $\left(7 \mathrm{a} 13^{\circ} \mathrm{C}\right)$ (Castro \& Cortez, 2003) -, são essenciais para a preservação da qualidade e maior tempo de prateleira.

A CEASA Campinas disponibiliza locação de câmara fria, porém distantes da área de comercialização aberta (denominada pedra), onde, principalmente, pequenos comerciantes utilizam esses espaços. No caso de atacadistas com lojas (denominadas boxes), alguns possuem sua própria câmara para refrigeração de produtos.

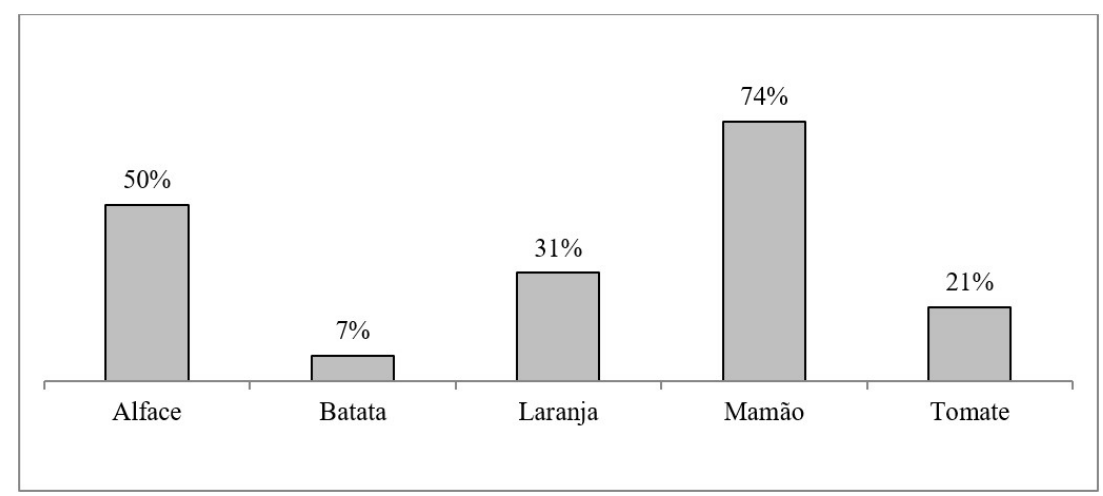

Figura 4 - Percentual de atacadistas que acondicionavam as FLV em câmara fria

No caso da alface, uma parcela fazia uso do caminhão refrigerado diretamente no local com forma de acondicionamento temporário, sendo uma prática realizada por 50\% desses atacadistas (Figura 4). Foi observado que, no caso do mamão, o uso de câmara fria para armazenamento do produto contribuiu para aumentar seu tempo de prateleira, segundo atacadistas. Os pequenos comerciantes não faziam uso do armazenamento em câmara fria disponíveis para locação em função do aumento do custo operacional.

Embora o custo de utilização da câmara fria possa parecer elevado, ele reduziria as perdas de produtos comercializados, podendo, em alguns casos, ser equivalente ou mesmo superior, elevando o ganho do atacadista. De acordo com Chitarra \& Chitarra (2005), o uso de técnicas complementares ao armazenamento refrigerado, tais como o uso de filme de polietileno, de cera, fécula e fungicidas, pode minimizar as injúrias em FLV. 


\subsubsection{Tipos de embalagem}

As FLV, em suas formas frescas, contêm alta porcentagem de água, portanto o desenvolvimento de embalagens específicas para cada tipo de produto é importante para sua seguridade e integridade física e fisiológica. As embalagens são essenciais para garantir a qualidade sanitária (ausência de perigos químicos, físicos e microbiológicos) ao longo da cadeia (Freire Junior \& Soares, 2014).

Ščetar et al. (2010) explicam que determinadas frutas deveriam ser embrulhadas separadamente em lenços de papel ou papel-manteiga, o que, consequentemente, melhoraria a proteção física e a redução da propagação de agentes patológicos dentro de um pacote. Além disso, as caixas plásticas devem se alinhar umas às outras, a fim de evitar espaços vazios, favorecendo, assim, a ventilação adequada para o conteúdo durante o transporte e o armazenamento, ao mesmo tempo que suas dimensões e seu design devem ser adequados às opções disponíveis de transporte, a fim de carregar de forma ordenada e segura. Os empilhamentos também devem ser observados, principalmente em caixas de papelão.

No futuro, as embalagens deverão incorporar materiais inteligentes e convencionais, agregando valor e benefícios em toda a cadeia de perecíveis. Porém, a adoção de materiais inteligentes precisa estar atrelada a preços, pois as embalagens precisam ser baratas em relação ao valor do produto, confiáveis, precisas e práticas, proporcionando o menor impacto ambiental possível (Ščetar et al., 2010).

A utilização de embalagens adequadas não foi unânime à maioria dos produtos; somente a batata possuía o padrão de movimentação de $100 \%$ com a utilização de sacarias. Para a alface, $100 \%$ dos atacadistas trabalhavam com embalagem de madeira, dos quais $83,3 \%$ também trabalhavam com embalagens plásticas.

Para o tomate, $89,5 \%$ dos atacadistas optavam pela embalagem plástica, enquanto $10,5 \%$ preferiam a utilização de embalagem de papelão. No caso da laranja, a embalagem plástica era aceita por $92 \%$ dos atacadistas, $15 \%$ aceitavam a saca com embalagem e $15 \%$ aceitavam o papelão para o acondicionamento. Vale ressaltar que, nesse caso, a aceitação de um tipo de embalagem não necessariamente reflete o seu uso exclusivo, assim como no caso do mamão, em que $47 \%$ aceitavam a utilização de embalagens de madeira, $11 \%$ aceitavam a utilização de plástico, $63 \%$ utilizavam o papelão e $5 \%$ ainda atuavam com a movimentação a granel.

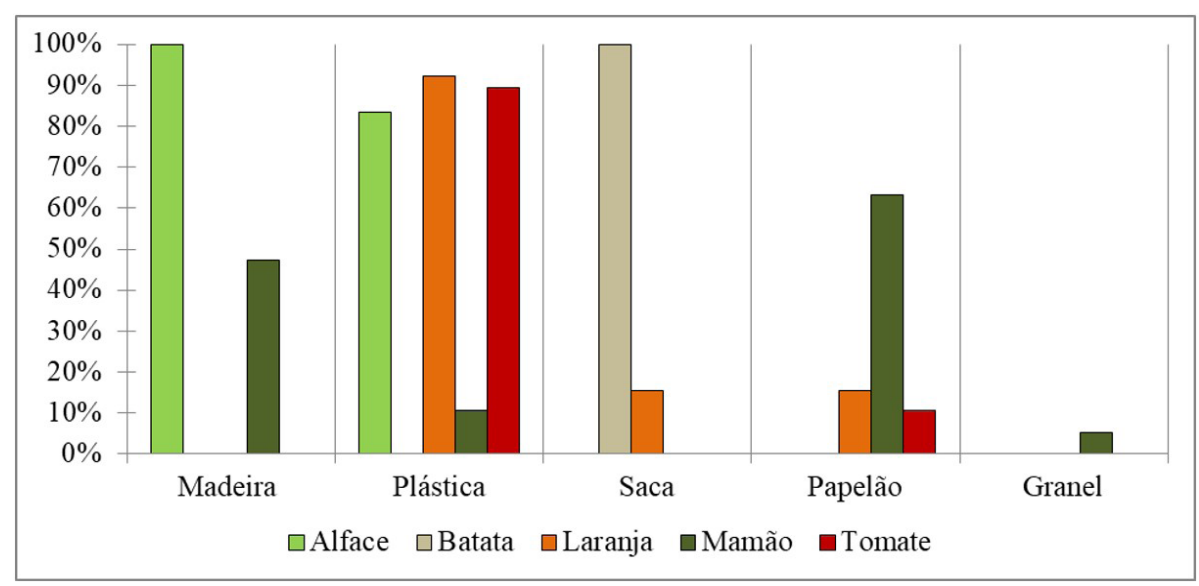

Figura 5 - Percentual das embalagens empregadas pelos atacadistas no transporte

O uso da tradicional caixa K (madeira), utilizada desde a Segunda Guerra Mundial, produz injúrias mecânicas em grande parte dos produtos nela acondicionados. Durante o transporte, as 
caixas sofrem impactos e vibrações. Nos carregamentos e nas descargas, elas são empilhadas ou retiradas, frequentemente, de forma inadequada (Vilela et al., 2003).

As caixas de madeiras, predominantemente utilizadas para a alface (Figura 5), não são adequadas, pois agentes patológicos estão presentes em suas fissuras, podendo ocasionar contaminação do alimento e perdas durante a manipulação. Apesar de os atacadistas fazerem uso de sacos plásticos para revestir a caixa, ainda assim a embalagem não é apropriada, pois inibe a respiração adequada. Como a alface possui baixo valor agregado, o custo com diferentes embalagens eleva o preço do produto. Segundo os atacadistas entrevistados, não era possível repassar esses custos ao consumidor.

\subsubsection{Troca de embalagem}

A troca de embalagem feita pelos comerciantes ocorre, principalmente, por dois motivos: seleção de produtos (injúrias, formato, tamanho e maturação) e uso de embalagens de menor volume para atender às demandas específicas.

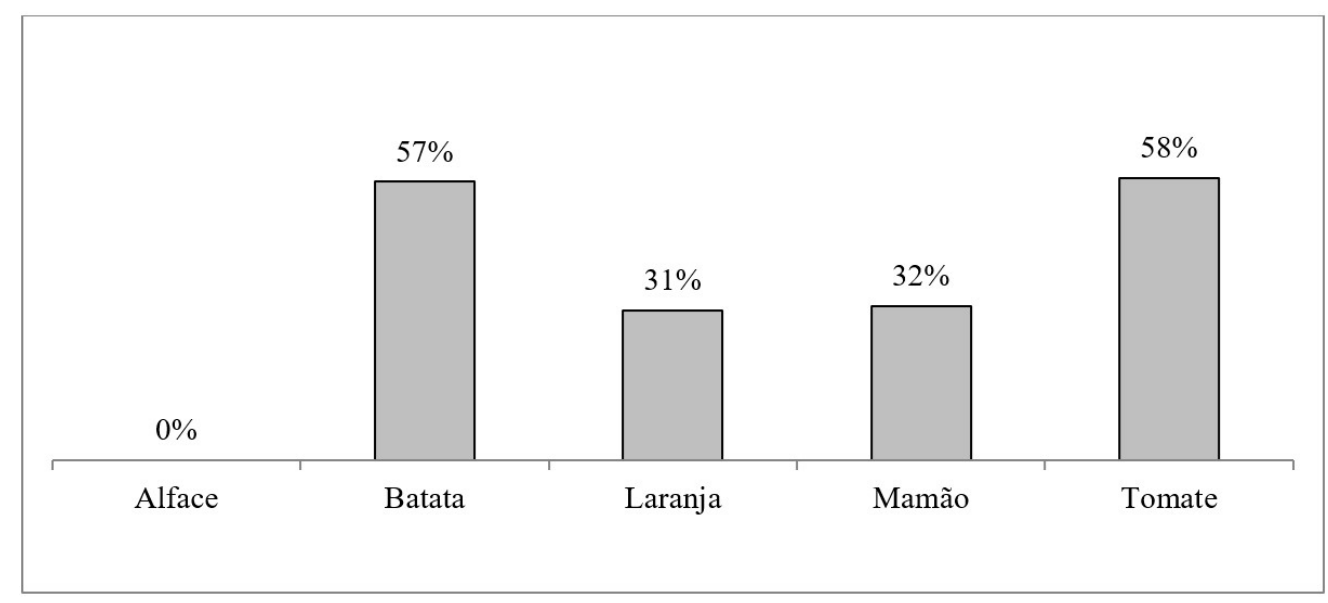

Figura 6 - Percentual de atacadistas que fazem troca de embalagem

A troca de embalagem ocorreu, principalmente, na comercialização da batata e do tomate com manipulação acima de 50\% (Figura 6). No caso da batata, existem atacadistas que transferiam das sacas de $50 \mathrm{~kg}$ para sacas menores e selecionavam as de melhor qualidade, facilitando a comercialização do produto e agregando valor. Para o tomate, a manipulação ocorreu, sobretudo, na troca da caixa do produtor rural para a caixa do atacadista, em que, durante a transição, eram feitas a avaliação da qualidade do produto e a padronização de tamanhos. Mesmo com um percentual menor, o mamão com 32\% de manipulação possuía manuseio de troca de embalagem quando ocorria a transferência das cargas recebidas a granel para caixas menores, de forma a melhorar a exposição do produto. A laranja também passou por troca de embalagem em $31 \%$ dos casos; quando chegava a granel, era beneficiada e acondicionada em caixas, ou, assim como a batata, era transferida para sacas menores.

\subsubsection{Manipulação da carga}

O manuseio pós-colheita em toda a cadeia logística das FLV é um fator crítico quando se discute a preservação da qualidade do alimento (Freire Junior \& Soares, 2014). Entende-se que, 
quanto maior a ação humana na manipulação de alimentos perecíveis, maiores são as chances de contaminação e deterioração causadas por injúrias nesse processo.

Para que o produto chegue ao destino em boas condições, é necessário que ocorra o mínimo de manuseio, que sejam cumpridas as regras sanitárias nas operações de carga e descarga, além do uso de tecnologias que reduzam a manipulação por ação humana. Produtos transportados com pragas desde o campo, maturação avançada e injúrias são mais sensíveis à deterioração por manipulação. Conforme explica Freire Junior \& Soares (2014), as perdas de alimentos podem ser significativamente reduzidas por meio da capacitação dos agricultores, por meio de boas práticas agrícolas e manuseio pós-colheita.

No processo de carregamento, a alocação das caixas deve ser feita, preferencialmente, quando estas estiverem com o volume preenchido, a fim de evitar a compactação das camadas inferiores de frutos. O tempo entre o início do carregamento e a descarga no destino deve ser o menor possível. Além disso, quando as distâncias entre origem-destino são menores, a colheita pode ser feita mais próxima ao ponto ótimo de amadurecimento do fruto, o que, neste caso, contribui para a qualidade, propriedades organolépticas e sensoriais.

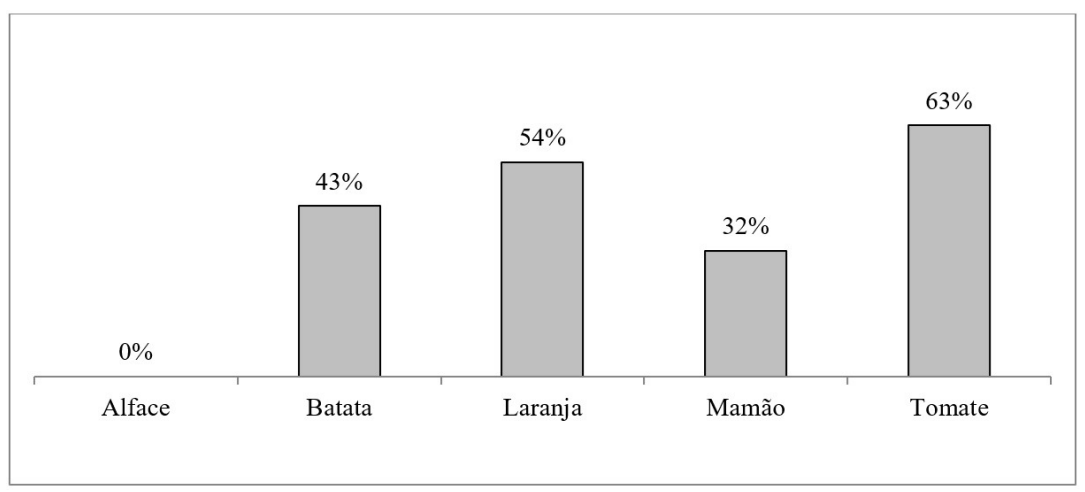

Figura 7 - Percentual de atacadistas que manipulavam carga

O tomate era o produto que possuía maior manipulação da carga, seguido da laranja, da batata e do mamão (Figura 7). No caso do tomate, a necessidade de troca de caixas fazia com que houvesse o aumento do número de manuseios. As injúrias observadas nos tomates comercializados ocorriam por danos mecânicos que favoreciam a ação de patógenos e que encontravam um ambiente propício para sua proliferação, alta temperatura e umidade. A manipulação do mamão também foi observada, principalmente, em casos de cargas a granel.

Embora, para o caso da alface, a manipulação fosse de $0 \%$, durante a aplicação do questionário foi possível observar in loco volumes significativos de folhas descartadas, por estarem murchas ou deterioradas, fato que pode estar associado à manipulação durante a comercialização.

\subsubsection{Etapas associadas às perdas}

Existe uma grande dificuldade em quantificar as perdas decorrentes durante a logística de transporte de FLV, pois o nível de controle ainda é muito baixo quando comparado com outros setores produtivos. Além disso, a quantificação depende, principalmente, da participação dos comerciantes e de sistemas de informação em tempo real para o levantamento dos dados.

Os atacadistas foram questionados sobre quais fatores que, durante o transporte, poderiam estar mais associados a possíveis causas das perdas e dos desperdícios. A percepção dos atacadistas está sintetizada na Tabela 4. 
Tabela 4 - Fatores associados às perdas na opinião dos atacadistas

\begin{tabular}{|c|c|c|c|c|}
\hline Alface & Batata & Laranja & Mamão & Tomate \\
\hline Acondicionamento & Acondicionamento & Clima & Acondicionamento & Acondicionamento \\
\hline Clima & Manuseio & $\begin{array}{c}\text { Condições das } \\
\text { estradas }\end{array}$ & $\begin{array}{l}\text { Caminhão } \\
\text { quebrado }\end{array}$ & Clima \\
\hline \multirow[t]{6}{*}{$\begin{array}{l}\text { Falta de } \\
\text { refrigeração }\end{array}$} & & Manuseio & Clima & $\begin{array}{c}\text { Condições das } \\
\text { estradas }\end{array}$ \\
\hline & & & $\begin{array}{c}\text { Condições das } \\
\text { estradas }\end{array}$ & Manuseio \\
\hline & & & $\begin{array}{l}\text { Embalagem } \\
\text { Falta de } \\
\text { refrigeração }\end{array}$ & Tempo da viagem \\
\hline & & & Manuseio & \\
\hline & & & Praga & \\
\hline & & & Tempo da viagem & \\
\hline
\end{tabular}

O fator clima foi citado para quatro dos produtos analisados (Tabela 4). Em geral, oscilações bruscas de temperatura e grande amplitude entre a máxima e a mínima podem acelerar a perecibilidade do produto. É o caso da alface, que, por se tratar de uma hortaliça folhosa de pós-colheita curta, sua produção concentra-se em zonas chamadas de cinturões verdes - áreas próximas às regiões metropolitanas. Quando a alface é transportada em caminhões-baú sem o uso da refrigeração, em condição de alta temperatura, o processo de deterioração é acelerado, fazendo com que o produto perca o vigor.

O acondicionamento também foi citado para quatro dos produtos (Tabela 4). No caso da batata, se as sacas não forem bem posicionadas no caminhão, o balanço decorrente do transporte faz com que ocorra atrito entre os produtos, levando a injúrias. Isso facilita a ocorrência de fungos e bactérias, podendo provocar a deterioração do produto. Essa perda não intencional também está atrelada ao fator manuseio, já que o acondicionamento, em sua maioria, é feito por mão de obra não treinada. No caso da laranja, do mamão e do tomate, dadas suas características, podem sofrer deformidades em sua forma quando pressionados. A laranja perde aparência comercial para consumo in natura, mas ainda consegue ser comercializada para indústrias de suco de laranja, contudo com menor valor de mercado. Entretanto, o mamão e o tomate, por serem frágeis, apresentam aceleração no processo de deterioração, diminuindo o tempo de prateleira e ocasionado perdas.

Fatores como condições das estradas e tempo de viagem também contribuem para o processo de injúrias às FLV (Tabela 4). Estradas de terra aumentam a movimentação do caminhão e também o tempo de viagem. Além disso, vias malconservadas, com buracos e ondulações, elevam a trepidação do veículo.

Os comerciantes também relataram a incidência de ataque de patógenos provenientes da produção (Tabela 4), que, durante o transporte, por ocasião, principalmente, da temperatura, contribuem para o surgimento de manchas, ferrugens e desenvolvimento de larvas que crescem dentro do alimento. A consequência é a perda da qualidade do produto, não só aparente (cor, brilho, tamanho, forma, integridade, consistência e defeitos), mas também de sabor e textura (dureza, maciez e suculência), aroma e valor nutritivo (Freire Junior \& Soares, 2014).

Como forma de conter as perdas e os desperdícios, uma iniciativa bastante valorizada pelos atacadistas é a doação de alimentos que não possuem aparência para a comercialização, mas que ainda podem ser utilizados para o consumo. Na CEASA Campinas, existe o ISA, que visa combater as perdas e os desperdícios de alimentos, selecionando e distribuindo os alimentos 
doados pelos atacadistas para a população carente, promovendo, desta forma, a segurança alimentar e nutricional.

Os resultados desta pesquisa mostraram diferentes gargalos a serem superados, principalmente relacionados à manipulação e à prática do transporte refrigerado. A existência do banco de alimentos é capaz de reduzir o desperdício, uma vez que promove o aproveitamento do excedente de frutas e vegetais que perderam valor comercial, mas que ainda apresentam qualidade para alimentação. De modo geral, o controle das perdas e dos desperdícios é capaz de maximizar a oferta de alimentos.

\section{Conclusões}

O presente estudo forneceu uma análise sistêmica das complexidades associadas às práticas operacionais da logística de distribuição das principais FLV comercializadas na CEASA Campinas, a saber: alface, batata, laranja, mamão e tomate. Como resultado, foi possível traçar estratégias que tenham como objetivo promover a redução dos índices de perdas e desperdícios de alimentos, além de colaborar para o aumento da oferta de produtos frescos e de qualidade superior. Por fim, as discussões sobre iniciativas que mitiguem as perdas de produtos perecíveis, particularmente na etapa de distribuição, e que facilitem o acesso aos alimentos também se inserem como uma ação capaz de promover a segurança alimentar e nutricional das pessoas em situação de vulnerabilidade social.

As variáveis relacionadas ao transporte (tipo, agente responsável, rastreabilidade), acondicionamento (câmara fria, tipo de embalagem, troca de embalagem) e manuseio póscolheita foram as operações logísticas que, quando não implantadas de forma eficiente, podem contribuir para os altos índices de perdas de alimentos.

A adoção de práticas mais eficientes, como o uso do transporte refrigerado, o emprego da rastreabilidade, o acondicionamento em câmaras frias e o uso de embalagens apropriadas que minimizem o manuseio da carga, é essencial para a preservação da qualidade do produto e mitigação das perdas. Isto vai ao encontro da percepção dos atacadistas entrevistados nesta pesquisa, que também avaliaram que essas eram as práticas capazes de melhorar a eficiência logística da distribuição de alimentos.

Além disso, o uso de novas tecnologias que apoiem o setor, como o uso de softwares especializados, e o treinamento envolvendo agentes de toda a cadeia são pontos de melhoria para as operações logísticas, aumentando o tempo de prateleira dos alimentos para comercialização.

Em vista da perspectiva do aumento do consumo de alimentos in natura, a possibilidade de novos investimentos que promovam a expansão da infraestrutura para produtos perecíveis e a modernização da frota de veículos e equipamentos dedicados criam um cenário promissor para os setores público e privado.

Ainda que a pesquisa tenha apontado as práticas operacionais, uma limitação do estudo foi a ausência da mensuração quantitativa das perdas, uma vez que os atacadistas não faziam o registro do volume de produtos que eram descartados.

Outro fator limitante foram os questionários aplicados a uma amostra limitada de atacadistas e a um grupo de produtos, por isso podem ser feitas novas pesquisas com outros produtos selecionados, bem como a ampliação da amostra de atacadistas.

Novas questões emergiram ao longo da pesquisa e podem ser base para estudos futuros que visem ampliar as discussões sobre a segurança alimentar, como a necessidade de avaliação das práticas e operações durante a produção e colheita de FLV nos estabelecimentos rurais, para 
que, desde do início dessas cadeias de suprimentos, as ações e condutas sejam direcionadas de forma a mitigar as perdas e os desperdícios de alimentos.

\section{Referências}

Akintoye, A., McIntosh, G., \& Fitzgerald, E. (2000). A survey of supply chain collaboration and management in the UK construction industry. European Journal of Purchasing \& Supply Management, 6(3-4), 159-168.

Associação Nacional dos Fabricantes de Implementos Rodoviários - ANFIR. (2020). Desempenho do setor. Recuperado em 27 de dezembro de 2020, de https://www.anfir.org.br/dados-dosetor.php?selAno=2020

Beebe, J. (1995). Basic concepts and techniques of rapid appraisal. Human Organization, 54(1), 42-51.

Belik, W. B., Cunha, A. R. A. A., \& Costa, L. A. (2012). Crise dos alimentos e estratégias para a redução do desperdício no contexto de uma política de segurança alimentar e nutricional no Brasil. Planejamento e Políticas Públicas, (38).

Bloemhof, J. M., \& Soysal, M. (2017). Sustainable food supply chain design. In Y. Bouchery, C. Corbett, J. C. Fransoo \& T. Tan (Eds.), Sustainable Supply Chains (pp. 395-412). Springer: Cham.

Castro, L. R. D., \& Cortez, L. A. B. (2003). Aplicação da refrigeração na conservação pós-colheita do tomate. In Proceedings of the 3. Encontro de Energia no Meio Rural. Campinas: AGRENER. Recuperado em 27 de dezembro de 2020, de http://www.proceedings.scielo.br/scielo. php?script=sci_arttext\&pid=MSC0000000022000000100011\&lng=en\&nrm=iso

Cattaneo, A., Sánchez, M. V., Torero, M., \& Vos, R. (2020). Reducing food loss and waste: Five challenges for policy and research. Food Policy, 98, 101974.

Central de Abastecimento de Campinas - CEASA Campinas. (2020). Mercado de hortifrútis. Recuperado em 27 de dezembro de 2020, de http://www.ceasacampinas.com.br/mercadohortifrutis

Chitarra, M. I. F., \& Chitarra, A. B. (2005). PósロColheita de Frutas e Hortaliças: Fisiologia e Manuseio (2nd ed.). Lavras: UFLA.

Companhia Nacional de Abastecimento - CONAB. (2020). Prohort - Simab. Recuperado em 27 de dezembro de 2020, de http://dw.ceasa.gov.br/

Companhia Nacional de Abastecimento - CONAB. (2021). Informativo da classificação anual de comercialização por quantidades da CEASA no período: 2019/2020 Recuperado em 27 de maio de 2021, de http://www3.ceasa.gov.br/siscomweb/?page=reports.relatorio_classificacao_ hortigranjeiro_ranking\&retTO=consulta_relatorio_classificacao_hortigranjeiro_ranking

Conselho Federal de Administração - CFA. (2019). Empreender: mercado de alimentação saudável cresce no Brasil. Recuperado em 05 de março de 2021, de https://cfa.org.br/ empreender-mercado-alimentacao-saudavel-cresceno-brasil/

Council of Supply Chain Management Professionals - CSCMP. (2020). CSCMP supply chain management definitions and glossary. Recuperado em 07 de dezembro de 2020, de https:// cscmp.org/CSCMP/Educate/SCM_Definitions_and_Glossary_of_Terms.aspx

Cunha, A. R. (2015). Dimensionando o passeio das mercadorias: uma análise através dos dados do Prohort. Revista de Política Agrícola, 24(4), 55-63. 
Cunha, A. R. A. D. A. (2006). Dimensões estratégicas e dilemas das Centrais de Abastecimento no Brasil. Revista de Política Agrícola, 15(4), 37-46.

Cunha, A. R. A. D. A., \& Belik, W. (2012). Entre o declínio e a reinvenção: atualidade das funções do sistema público atacadista de alimentos no Brasil. Revista de Economia e Sociologia Rural, 50, 435-454.

Dunn, T. (1994). Rapid rural appraisal: a description of the methodology and its application in teaching and research at Charles Sturt University. Rural Society, 4(3-4), 30-36.

Elias, A. A. (2008). Towards a shared systems model of stakeholders in environmental conflict. International Transactions in Operational Research, 15(2), 239-253.

Elias, A. A., \& Davis, D. (2018). Analysing public sector continuous improvement: a systems approach. International Journal of Public Sector Management, 31(1), 2-13.

Fehr, M., \& Romão, D. C. (2001). Measurement of fruit and vegetable losses in Brazil: a case study. Environment, Development and Sustainability, 3(3), 253-263.

Food and Agriculture Organization of the United Nations - FAO. (2011). Global food losses and food waste. Extent, causes and prevention. Düsseldorf: FAO.

Food and Agriculture Organization of the United Nations - FAO. (2016). The state of food and agriculture. Climate change, agriculture and food security. Rome: FAO.

Food and Agriculture Organization of the United Nations - FAO. (2019). The state of food and agriculture. Moving forward on food loss and waste reduction. Rome: FAO.

Freire Junior, M., \& Soares, A. G. (2014). Orientações quanto ao manuseio pré e pós-colheita de frutas e hortaliças visando a redução de suas perdas. Brasília: Embrapa Agroindústria de Alimentos.

Gustavsson, J., Cederberg, C., Sonesson, U., \& Emanuelsson, A. (2013). The methodology of the FAO study: Global Food Losses and Food Waste-extent, causes and prevention - FAO, 2011. Rome: FAO.

Henz, G. P. (2018). Perdas pós-colheita de produtos hortícolas no Brasil. In Centro de Estudos e Debates Estratégicos Consultoria Legislativa (Org.). Perdas e desperdício de alimentos: estratégias para redução (pp. 67-86). Brasília: Câmara dos Deputados - Edições Câmara.

Hospido, A., Canals, L. M., McLaren, S., Truninger, M., Edwards-Jones, G., \& Clift, R. (2009). The role of seasonality in lettuce consumption: a case study of environmental and social aspects. The International Journal of Life Cycle Assessment, 14(5), 381-391.

Instituto Brasileiro de Geografia e Estatística - IBGE. (2019a). Pesquisa de Orçamentos Familiares - POF 2017-2018. Recuperado em 07 de dezembro de 2020, de https://biblioteca.ibge.gov. br/visualizacao/livros/liv101742.pdf

Instituto Brasileiro de Geografia e Estatística - IBGE. (2019b). Levantamento Sistemático da Produção Agrícola. Banco de Dados SIDRA. Recuperado em 27 de dezembro de 2020, de https://sidra.ibge.gov.br/tabela/1001\#resultado

Kluge, R. A., Jomori, M. L. L., Edagi, F. K., Jacomino, A. P., \& Aguila, J. A. D. (2007). Danos de frio e qualidade de frutas cítricas tratadas termicamente e armazenadas sob refrigeração. Revista Brasileira de Fruticultura, 29(2), 233-238.

Kumar, D., \& Kalita, P. (2017). Reducing postharvest losses during storage of grain crops to strengthen food security in developing countries. Foods, 6(1), 8. 
Lana, M. M. (2018). Perdas e desperdício de hortaliças no Brasil. In In Centro de Estudos e Debates Estratégicos Consultoria Legislativa (Org.). Perdas e desperdício de alimentos: estratégias para redução (pp. 87-114). Brasília: Câmara dos Deputados - Edições Câmara.

Maani, K. E., \& Cavana, R. Y. (2000). Systems thinking and modelling: understanding change and complexity. Auckland: Pearson Education.

Mankiw, N. G. Principles of economics. Boston: Cengage Learning, 2014.

Marcomini, G. R., \& Patino, M. T. O. (2020). Viabilidade econômica da colheita mecanizada de batata no estado de São Paulo. Boletim Técnico, 3(1).

Mason-D'Croz, D., Bogard, J. R., Sulser, T. B., Cenacchi, N., Dunston, S., Herrero, M., \& Wiebe, K. (2019). Gaps between fruit and vegetable production, demand, and recommended consumption at global and national levels: an integrated modelling study. The Lancet. Planetary Health, 3(7), e318-e329.

Muralikumar, M. D., \& Nardi, B. (2018). Addressing limits through tracking food. In Proceedings of the 2018 Workshop on computing within Limits (pp. 1-9). New York: ACM.

Oliveira, S. P., Castro, F. T., Tabai, K. C., Barbosa, C., Mendes, L. L., Penha, E. D. M., \& Góes, H. D. A. (2008). Manual para comerciantes e manipuladores de frutas, legumes e verduras: três passos para o sucesso das vendas. Brasília: Embrapa Agroindústria de Alimentos.

Porat, R., Lichter, A., Terry, L. A., Harker, R., \& Buzby, J. (2018). Postharvest losses of fruit and vegetables during retail and in consumers' homes: Quantifications, causes, and means of prevention. Postharvest Biology and Technology, 139, 135-149.

Rinaldi, M. M. (2011). Perdas pós-colheita devem ser consideradas. Planaltina: Embrapa Cerrados.

Saath, K. C. D. O., \& Fachinello, A. L. (2018). Crescimento da demanda mundial de alimentos e restrições do fator terra no Brasil. Revista de Economia e Sociologia Rural, 56, 195-212.

Ščetar, M., Kurek, M., \& Galić, K. (2010). Trends in fruit and vegetable packaging-a review. Hrvatski Casopis za Prehrambenu Tehnologiju, Biotehnologiju i Nutricionizam, 5(3-4), 69-86.

Senge, P. M. (1990). The art and practice of the learning organization. Recuperado em 27 de dezembro de 2020, de http://www.seeing-everything-in-a-new-way.com/ uploads/2/8/5/1/28516163/peter-senge-the-fifth-discipline.pdf

Silva, O. F., \& Soares, A. (2001). Recomendações para prevenção de perdas pós-colheita do mamão. Brasília: Embrapa Agroindústria de Alimentos.

Sousa, M. G. K., \& Aguiar, L. P. (2019). A vigilância sanitária e o comércio de alimentos em eventos de massa. Cadernos ESP, 13(2), 38-53.

Sterman, M. B. (2000). Basic concepts and clinical findings in the treatment of seizure disorders with EEG operant conditioning. Clinical EEG, 31(1), 45-55.

Sukati, I., Hamid, A. B., Baharun, R., \& Yusoff, R. M. (2012). The study of supply chain management strategy and practices on supply chain performance. Procedia: Social and Behavioral Sciences, 40, 225-233.

Triches, R. M. (2020). Dietas saudáveis e sustentáveis no âmbito do sistema alimentar no século XXI. Saúde em Debate, 44, 881-894.

United Nations - UN. Department of Economic and Social Affairs, Population Division. (2019). World Population Prospects 2019: Highlights. New York: United Nations.

Vilela, N. J., Lana, M. M., Nascimento, E. F., \& Makishima, N. (2003). O peso da perda de alimentos para a sociedade: o caso das hortaliças. Horticultura Brasileira, 21(2), 142-144. 
Volpato, G. L. (2013). Ciência: da filosofia à publicação. São Paulo: Cultura Acadêmica.

Wognum, P. N., Bremmers, H., Trienekens, J. H., van der Vorst, J. G., \& Bloemhof, J. M. (2011). Systems for sustainability and transparency of food supply chains-Current status and challenges. Advanced Engineering Informatics, 25(1), 65-76.

World Health Organization - WHO. (2019). World health statistics 2019: monitoring health for the SDGs, sustainable development goals. Geneve: WHO.

Yahia, E. M., García-Solís, P., \& Celis, M. E. M. (2019). Contribution of fruits and vegetables to human nutrition and health. In E. M. Yahia \& A. Carrillo-López (Eds.), Postharvest physiology and biochemistry of fruits and vegetables (pp. 19-45). Duxford: Woodhead Publishing. 


\section{Apêndice 1 - Roteiro das Entrevistas}

PERMISSIONÁRIO:

Nome do ENTREVISTADO: TEL:

Assinale quais desses produtos você comercializa na CEASA Campinas:

( ) ALFACE ( ) BATATA ( ) LARANJA ( ) MAMÃO ( ) TOMATE

Quem faz o transporte do campo até a CEASA Campinas?

( ) Você permissionário

( ) Transportadora ou ( ) Autônomo - contratado por você permissionário

( ) Transportadora ou ( ) Autônomo - contratado pelo produtor rural

( ) Produtor rural

() Outro. Explique

Quantas vezes por semana chega produto para você permissionário na CEASA Campinas?

\begin{tabular}{|c|c|}
\hline ALFACE & 1 ( ) 2( ) 3( ) 4( ) 5( ) ou ( )Mais vezes. Quantas? \\
\hline BATATA & 1 ( ) 2( ) 3( ) 4( ) 5( ) ou ( )Mais vezes. Quantas? \\
\hline LARANJA & 1 ( ) 2( ) 3( ) 4( ) 5( ) ou ( )Mais vezes. Quantas? \\
\hline MAMÃO & 1 ( ) 2( ) 3( ) 4( ) 5( ) ou ( )Mais vezes. Quantas? \\
\hline TOMATE & 1 ( ) 2( ) 3( ) 4( ) 5( ) ou ( )Mais vezes. Quantas? \\
\hline
\end{tabular}

Em que condições o transporte é feito do campo até a CEASA Campinas?

( ) Caminhão aberto - Lonado ( )

( ) Caminhão-baú

( ) Transporte refrigerado

( ) Outro tipo. Qual?

() Outro tipo. Qual?

Qual é a embalagem usada no transporte quando sai do campo até chegar à CEASA Campinas?

\section{ALFACE ( ) Nenhuma-granel ( ) Caixa madeira ( ) Caixa plástica ( ) Papelão ( ) Outra. Qual?}

BATATA ( ) Nenhuma-granel ( ) Caixa madeira ( ) Caixa plástica ( ) Papelão ( ) Outra. Qual?

LARANJA ( ) Nenhuma-granel ( ) Caixa madeira ( ) Caixa plástica ( ) Papelão ( ) Outra. Qual?

MAMÃO ( ) Nenhuma-granel ( ) Caixa madeira ( ) Caixa plástica ( ) Papelão ( ) Outra. Qual?

TOMATE () Nenhuma-granel ( ) Caixa madeira ( ) Caixa plástica ( ) Papelão ( ) Outra. Qual?

Qual é a perda de produto cada vez que chega carga para você permissionário na CEASA Campinas?

ALFACE 1 caixa( ) 2 caixas( ) Se mais caixas, quantas? () Se menos, quantas?()

BATATA 1 caixa( ) 2 caixas( ) Se mais caixas, quantas?( ) Se menos, quantas?( )

LARANJA 1 caixa( ) 2 caixas( ) Se mais caixas, quantas?( ) Se menos, quantas?( )

MAMÃO 1 caixa( ) 2 caixas( ) Se mais caixas, quantas?( ) Se menos, quantas?( )

TOMATE 1 caixa( ) 2 caixas( ) Se mais caixas, quantas?( ) Se menos, quantas?( )

Quando o produto chega para você permissionário na CEASA Campinas, você troca de embalagem ou comercializa na mesma embalagem que veio dentro do caminhão? ( )NÃO TROCO - ( )TROCO. Se troca, qual a embalagem que usa:

$\begin{array}{cl}\text { ALFACE } & \text { ( ) Nenhuma-granel ( ) Caixa madeira ( ) Caixa plástica ( ) Papelão () Outra. Qual? } \\ \text { BATATA } & \text { ( ) Nenhuma-granel ( ) Caixa madeira ( ) Caixa plástica ( ) Papelão ( ) Outra. Qual? } \\ \text { LARANJA } & \text { ( ) Nenhuma-granel ( ) Caixa madeira ( ) Caixa plástica ( ) Papelão ( ) Outra. Qual? } \\ \text { MAMÃO } & \text { () Nenhuma-granel ( ) Caixa madeira ( ) Caixa plástica ( ) Papelão ( ) Outra. Qual? } \\ \text { TOMATE } & \text { ( ) Nenhuma-granel ( ) Caixa madeira ( ) Caixa plástica ( ) Papelão ( ) Outra. Qual? }\end{array}$


Qual é o volume (kg/mês) que você compra para ser comercializado na CEASA Campinas?

\section{ALFACE}

BATATA

LARANJA

MAMÃO

TOMATE

Quais são as cidades de origem (onde são produzidos) dos produtos que são comercializados na CEASA Campinas por você, informando os meses:

Fev.:
Mar.:
Abr.:
Maio:
Jun.:
Jul.:
Ago.:
Set.:
Out.:
Nov.:
Dez.:

A empresa possui câmara fria ou outro equipamento (climatização ou refrigeração) para a conservação ou o armazenamento dos produtos? Ou possui acesso?

( ) Não tenho e não possuo acesso.

( ) Sim, tenho acesso a equipamentos. Qual?

( ) Sim, tenho equipamentos. Qual?

A empresa faz a classificação ou a reclassificação dos produtos quando chega à CEASA?

( ) Não

( ) Sim. Qual? ( ) Classificação ( ) Reclassificação

A empresa trabalha com produtos com algum tipo de tratamento pós-colheita (lavagem, secagem, enceramento, seleção, embalados)?

( ) Não

( ) Sim. Quais?

( ) Não sabe informar

A empresa trabalha com produtos com algum tipo de manipulação para a comercialização (seleção, embalados, entre outros)?

( ) Não ( ) Sim: Quais?

Qual etapa do transporte, desde que sai do campo até chegar à CEASA Campinas, está associada a maiores perdas ou que contribui para elas (Ex. murcha, danos mecânicos, podridão, entre outras):

( ) Transporte ( ) Manuseio do produto pelo produtor rural

( ) Manuseio do produto (quando chega à CEASA) ( ) Mau dimensionamento da compra

() Outro

Desde fevereiro de 2019, no Brasil, passou a ser obrigatória a rastreabilidade de frutas, raízes, tubérculos e hortaliças. Os produtos que você comercializa já estão sendo rastreados?

( ) Não ( ) Sim. Se sim, quem faz a rastreabilidade?

( ) Você permissionário 
( ) Terceiro contratado por você permissionário

( ) Terceiro contratado pelo produtor

() Produtor

( ) Outro. Explique 